\title{
Pseudolaric acid B induced autophagy, but not apoptosis, in MRC5 human fibroblast cells
}

\author{
YUE WANG ${ }^{1,2^{*}}$, HONGMEI GAO $^{3 *}$, TING WU $^{4}$, ZENGYAN WANG $^{5}$, FENGMEI SONG $^{6}$, \\ ANTIAN CHEN $^{7}$, JING ZHANG ${ }^{7}$, WENYAN ZHANG ${ }^{1}$, HUI ZHANG ${ }^{2}$ and JINGHUA YU ${ }^{1}$
}

\begin{abstract}
${ }^{1}$ Research Institute of Virology and AIDS Research, The First Hospital of Jilin University, Jilin University, Changchun, Jilin 130021; ${ }^{2}$ Chemistry of Traditional Chinese Medicine, College of Pharmacy, Changchun University of Chinese Medicine, Changchun, Jilin 130000; ${ }^{3}$ Medicinal Chemistry, College of Pharmacy, Changchun University of Chinese Medicine, Changchun, Jilin 130021; ${ }^{4}$ Neonatal Intensive Care Unit; ${ }^{5}$ Department of Internal Medicine, The First Hospital of Jilin University; ${ }^{6}$ Department of Experimental Pharmacology and Toxicology, School of Pharmacy; ${ }^{7}$ College of Medicine, Norman Bethune Health Science Center, Jilin University, Changchun, Jilin 130000, P.R. China
\end{abstract}

Received October 17, 2016; Accepted October 18, 2017

DOI: $10.3892 / \mathrm{ol} .2017 .7426$

\begin{abstract}
Autophagy and apoptosis are closely associated. In previous studies, pseudolaric acid B (PAB), a diterpene acid isolated from the root and trunk bark of Pseudolarix kaempferi Gordon (Pinaceae), was demonstrated to induce apoptosis in various cell lines. However, in L929 murine fibrosarcoma and SW579 human thyroid squamous cell carcinoma cells, only autophagy was induced. In the present study, another cell line, MRC5 human lung fibroblast cells, was identified in which PAB only induced autophagy. The relationship between apoptosis and autophagy subsequent to PAB treatment in MRC5 cells was explored. When autophagy was inhibited by 3-methyladenine (3MA), apoptosis was induced in the PAB-treated MRC5 cells. To study the mechanism for the promotion of apoptosis by $3 \mathrm{MA}$ in the PAB-treated cells, the expression of members from the apoptotic signal pathways was assessed. As Bcl-2, Bcl-2 associated X and pro-caspase-9 expression following PAB treatment was not affected by 3MA treatment, it was determined that apoptosis was induced independent of the mitochondrial pathway of apoptosis. As Fas and pro-caspase- 8 expression following PAB treatment were not altered by $3 \mathrm{MA}$, it was further determined that the death receptor pathway was not induced. However, the phosphorylation of c-Jun-N-terminal kinase and the expression of pro-caspase- 3 were upregulated, and the phosphorylation
\end{abstract}

Correspondence to: Dr Jinghua Yu, Research Institute of Virology and AIDS Research, The First Hospital of Jilin University, Jilin University, 519 Dongming Zhu Street, Changchun, Jilin 130021, P.R. China

E-mail: yjh-0-2002@163.com

${ }^{*}$ Contributed equally

Key words: pseudolaric acid B, apoptosis, autophagy of extracellular signal-regulated kinase downregulated, by the combination of PAB and 3MA treatment compared with PAB alone. It was also observed that $3 \mathrm{MA}$ did not affect the microtubule aggregation ability of PAB. Therefore, inhibiting autophagy in MRC5 cells did not affect the role of PAB in microtubule aggregation, while apoptosis was induced. This may present a strategy to enhance the anti-tumor effects of PAB.

\section{Introduction}

Pseudolaric acid B (PAB) is a diterpene acid isolated from the root and trunk bark of Pseudolarix kaempferi Gordon (Pinaceae), known as 'Tu-jin-pi' in Chinese, which is used to treat dermatological fungi infections. PAB has been demonstrated to exert potent cell growth inhibition in vitro in various tumor cell lines through cell cycle arrest, apoptosis or autophagy (1-6), although the mechanisms for this effect have yet to be completely characterized.

Apoptosis has been the focus of a large volume of research regarding anti-tumor drug development $(7,8)$. The major mechanisms of apoptosis include the extrinsic or Fas death receptor pathway, which activates caspase- 8 and -10 in response to external stimuli (9) and the intrinsic or mitochondrial pathway, which induces the cleavage of pro-caspase-9 in response to internal stimuli (10). In mammalian cells, mitogen-activated protein kinases, including stress-activated protein kinase, c-Jun-N-terminal kinase (Jnk), p38 and extracellular signal-regulated kinase (Erk), are associated with cell death or proliferation (11). Generally, the expression of Erk promotes inflammation, apoptosis, cell growth, differentiation and oncogenic transformation, whereas Jnk and p38 are implicated in cell growth and differentiation, and development $(12,13)$.

In addition to apoptosis, autophagy has also been studied as an anti-cancer drug mechanism. Autophagy is the process by which cellular components are delivered to lysosomes for bulk degradation (14). In some cases, autophagy may promote 
cell death, but autophagy typically promotes cell survival by enabling cells to adapt to stress conditions (15). The inhibition of apoptosis by autophagy has also been demonstrated to decrease the effect of antitumor drugs (16).

In the present study, it was demonstrated that the PAB treatment of MRC5 cells induced autophagy, and not apoptosis. Inhibiting autophagy promoted apoptosis through the upregulation of phosphorylated (p)-Jnk expression and the downregulation of p-Erk, whereas inhibiting autophagy had no effect on cell cycle arrest or microtubule aggregation as induced by PAB. Therefore, inhibiting autophagy did not affect the role of $\mathrm{PAB}$ in microtubule aggregation and promoted cell apoptosis; this may present a strategy for the application of PAB against tumors.

\section{Materials and methods}

Materials. PAB (National Institute for the Control of Pharmaceutical and Biological Products, Beijing, China) was dissolved in dimethyl sulfoxide (DMSO) to produce a stock solution. DMSO concentration was maintained below $0.01 \%$ in all cell culture to prevent any detectable effect on cell growth or death. Propidium iodide (PI), phalloidin-tetramethylrhodamine B isothiocyanate, monodansylcadaverine (MDC), 3-methyladenine (3MA), Hoechst 33258 and RNase A were purchased from Sigma-Alrich (Merck KGaA, Darmstadt, Germany). TRIzol ${ }^{\circledR}$ reagent was purchased from Invitrogen and the SuperScript ${ }^{\mathrm{TM}}$ III RT-PCR kit was from Thermo Fisher Scientific, Inc. (Waltham, MA, USA). The Power SYBR Green PCR Master mix was acquired from Applied Biosystems (Thermo Fisher Scientific, Inc). The mouse light chain (LC) 3A/B monoclonal (cat. no., 66139-1-AP), and rabbit Beclin-1 (cat. no., 11306-1-AP), Bcl-2 (cat. no., 12789-1-AP), ERK1/2 (cat. no., 16443-1-AP) and Bax (cat. no., 50599-2-Ig) were purchased from ProteinTech Group, Inc. (Chicago, IL, USA). The rabbit histone $\mathrm{H} 3$ antibody was from GenScript (cat. no., A01502-40, Piscataway, NJ, USA). JNK1/2 (cat. no., BA1648, MAPK8/9) antibody and MAPK14 (cat. no., BM4142, p38) antibody were from Boster Biological Technology (Pleasanton, CA, USA). Antibodies against caspase-3 (cat. no., SC-373730), caspase-8 (cat. no., SC-6136) and caspase-9 (cat. no., SC-8355), p-p38 (cat. no., SC-7973, D-8), p-Jnk (SC-6254, G-7) and p-Erk (cat. no., SC-9477, T-19), and alkaline phosphatase (AP) labeled-secondary antibodies (cat. nos., SC-358915 and SC-2057) were obtained from Santa Cruz Biotechnology, Inc. (Dallas, TX, USA).

Cell culture. MRC5 human lung fibroblast cells (cat. no., CCL-171) were obtained from American Type Culture Collection (Manassas, VA, USA) and were cultured in DMEM medium (Hyclone; GE Healthcare Life Sciences, Logan, UT, USA) supplemented with $10 \%$ fetal calf serum, 2 mM glutamine (both Gibco; Thermo Fisher Scientific, Inc.), $100 \mathrm{U} / \mathrm{ml}$ penicillin and $100 \mu \mathrm{g} / \mathrm{ml}$ streptomycin. The cells were maintained at $37^{\circ} \mathrm{C}$ with $5 \% \mathrm{CO}_{2}$ in a humidified atmosphere.

Observation of morphological changes by light microscopy. MRC5 cells ( $5 \times 10^{5}$ cells/well) were cultured in 6 well plates for $24 \mathrm{~h}$. Then $4 \mu \mathrm{M}$ PAB and/or $2 \mathrm{mM} 3 \mathrm{MA}$ were added, and the cells were incubated for a further $36 \mathrm{~h}$. Cell morphology was observed with phase contrast microscopy (Leica Microsystems $\mathrm{GmbH}$, Wetzlar, Germany).

Determination of DNA fragmentation by agarose gel electrophoresis. Cells were trypsinized; adherent and floating cells were collected by centrifugation at $1,000 \mathrm{xg}$ at $4^{\circ} \mathrm{C}$ for $5 \mathrm{~min}$. Further procedures were performed as described in a previous study (5).

Fluorescence staining of microtubule aggregation. MRC5 cells $\left(5 \times 10^{5}\right)$ were placed on cover slips in a 6-well plate. Following a 24-h incubation, they were treated with $4 \mu \mathrm{M}$ PAB and/or $2 \mathrm{mM} 3 \mathrm{MA}$ for $36 \mathrm{~h}$, washed with PBS, fixed in $3.7 \%$ formaldehyde, then rinsed three times in PBS. TritonX-100 $(0.8 \%)$ was added for $15 \mathrm{~min}$, then cells were stained with $5 \mathrm{mg} / \mathrm{ml}$ phalloidin-tetramethylrhodamine B isothiocyanate for $40 \mathrm{~min}$, rinsed once in PBS and stained with 5 mg/l Hoechst 33258 for $30 \mathrm{~min}$. The intensity of red staining was measured by fluorescence microscopy with an excitation wavelength of $584 \mathrm{~nm}$ and an emission filter of $607 \mathrm{~nm}$ (Leica Microsystems $\mathrm{GmbH}$ ). Changes in nuclear morphology were observed by fluorescence microscopy at the excitation wavelength of $350 \mathrm{~nm}$ and an emission filter of $460 \mathrm{~nm}$ (Leica Microsystems $\mathrm{GmbH}$ ).

Observation of MDC staining by fluorescence microscopy. MDC is a fluorescent compound that stains autophagic vacuoles. MRC5 cells were treated with $4 \mu \mathrm{M}$ PAB and/or $2 \mathrm{mM}$ $3 \mathrm{MA}$ for $36 \mathrm{~h}$, then were incubated with $0.05 \mathrm{mM} \mathrm{MDC}$ at $37^{\circ} \mathrm{C}$ for $1 \mathrm{~h}$. Following the incubation, cells were washed in PBS. Intracellular MDC was measured by fluorescence microscopy at an excitation wavelength of $380 \mathrm{~nm}$ and an emission filter of $525 \mathrm{~nm}$ (Leica Microsystems $\mathrm{GmbH}$ ).

Cell counting. Trypan Blue (Sigma-Aldrich; Merck KGaA) was used as a vital stain. Live cells appeared colorless and bright (refractile) under phase contrast and dead cells were stained blue and were non-refractile. Following staining with a final concentration of $0.2 \%$ trypan blue for $3 \mathrm{~min}$ at room temperature, live cells were visualized in four quadrants and counted using a hemocytometer with phase contrast microscopy (Leica Microsystems GmbH, Wetzlar, Germany).

Reverse transcription-quantitative polymerase chain reaction $(R T-q P C R)$. RNA was extracted from control and drug-treated cells using TRIzol as specified by the manufacturer's protocol. The RNA was treated with DNase (DNase I-RNase-Free; Ambion; Thermo Fisher Scientific, Inc.) to remove any contaminating DNA; 200 ng of total RNA was reverse-transcribed with oligo dT primers using the SuperScript ${ }^{\mathrm{TM}}$ III RT-PCR kit (Applied Biosystems; Thermo Fisher Scientific, Inc.) in a $20 \mu \mathrm{l}$ reaction, as specified by the manufacturer's protocol. For quantitative PCR, the template cDNA was added to a $20 \mu \mathrm{l}$ reaction with Power SYBR-Green PCR Master mix and $0.2 \mu \mathrm{M}$ of primers for the target genes and GAPDH.

The primer sequences were as follows: LC3A forwards, GCCTTTCAAGCAGCGGCGGAGC, and reverse, TTG GTCTTGTCCAGGACGGGCA; LC3B forwards, CAGCGT CTCCACACCAATCTCA, and reverse, AATTTCATCCCG AACGTCTCCT; Beclin-1 forwards, CTCCATTACTTACCA CAGCCCA, and reverse, GGATGAATCTGCGAGAGA 
A

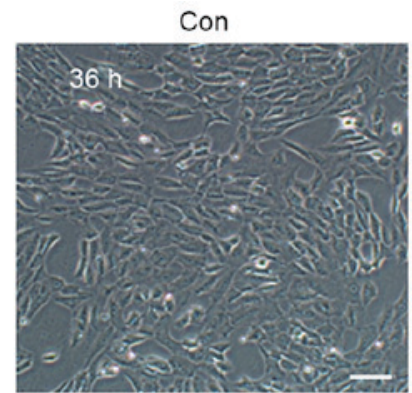

B
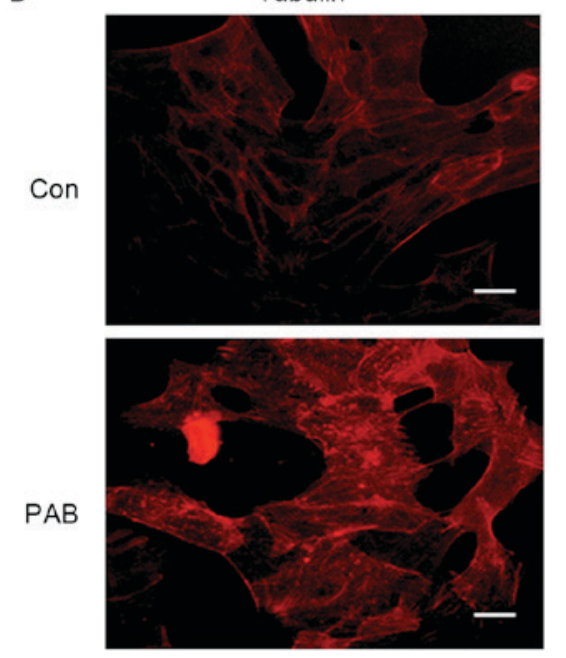

C

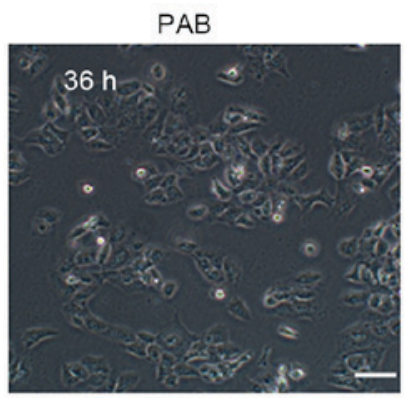

Nuclei
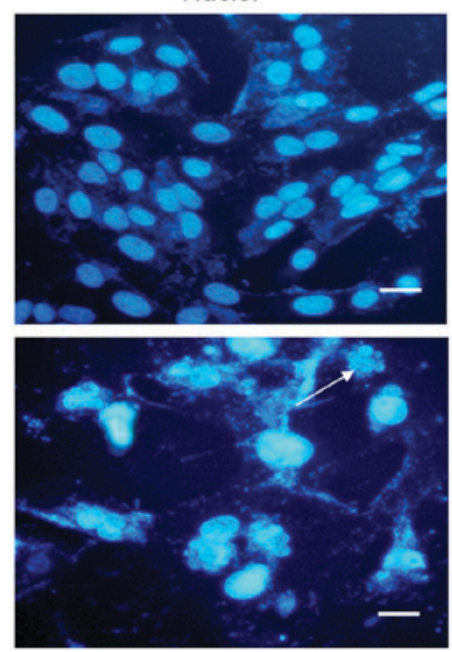
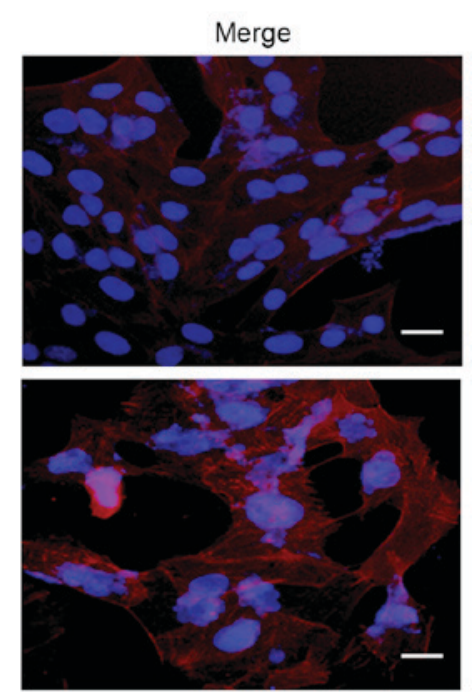

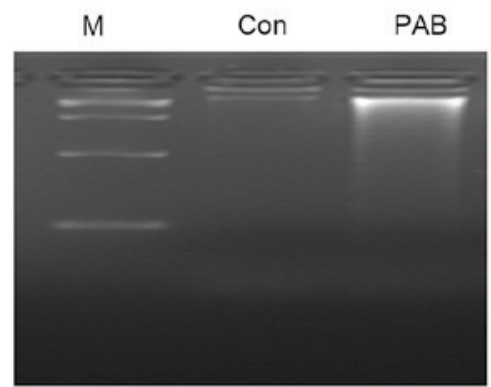

Figure 1. Apoptosis was not induced in MRC5 cells following treatment with PAB. (A) Morphological changes were observed in PAB-treated and control cells using phase contrast microscopy. Scale bar, $30 \mu \mathrm{m}$. (B) Cells were stained with phalloidin-tetramethylrhodamine B isothiocyanate and Hoechst 33258, and imaged with fluorescence microscopy, to determine morphological changes in the PAB-treated and control cells at $36 \mathrm{~h}$. Arrows indicate multinuclear cells. Scale bar, $60 \mu \mathrm{m}$. (C) No fragmentation of chromosomal DNA was observed in PAB-treated cells at $36 \mathrm{~h}$. All images are representative of three independent experiments. PAB, pseudolaric acid B; Con, control; M, marker.

CACC; GAPDH forwards, GCAAATTCCATGGCACCGT, and reverse, TCGCCCCACTTGATTTTGG.

Amplification was performed with a Prism 7000 machine (Applied Biosystems; Thermo Fisher Scientific, Inc.), with the following conditions: Initial denaturation at $95^{\circ} \mathrm{C}$ for $10 \mathrm{~min}$, then 40 cycles of $95^{\circ} \mathrm{C}$ for $15 \mathrm{sec}$ followed by $60^{\circ} \mathrm{C}$ for $1 \mathrm{~min}$. The fold changes relative to GAPDH were calculated using the $2^{-\Delta \Delta \mathrm{Cq}}$ method (17).

Cell cycle analysis by flow cytometry. Nuclear DNA content was measured using PI staining and fluorescence-activated cell sorting (FACS). Adherent cells were collected by treatment with trypsin and washed with PBS. Cells were fixed in $1 \mathrm{ml}$ of $70 \%$ ethanol overnight at $4^{\circ} \mathrm{C}$ and resuspended in staining buffer $(50 \mu \mathrm{g} / \mathrm{ml}$ PI and $20 \mu \mathrm{g} / \mathrm{ml}$ RNase, in PBS) for $2 \mathrm{~h}$ at $4^{\circ} \mathrm{C}$. The PI-stained cells were then analyzed using FACS (FACScan; BD Biosciences, Franklin Lakes, NJ, USA); $\leq 10^{4}$ cells were counted for each sample. Data analysis was performed using ModFit LT version 2.0 (Verity Software House, Inc., Topsham, ME, USA) $(18,19)$.

Western blot analysis of protein expression. MRC5 cells $\left(10^{6}\right)$ were cultured in in a $25-\mathrm{ml}$ culture flask for $24 \mathrm{~h}$, then treated with $4 \mu \mathrm{M}$ PAB and/or $2 \mathrm{mM} 3 \mathrm{MA}$ for $36 \mathrm{~h}$. Adherent and floating cells were collected and frozen at $-80^{\circ} \mathrm{C}$. Western blot analysis was performed as described in previous reports $(5,20-23)$. Protein expression was detected using the aforementioned primary antibodies (dilution, 1:1,000) followed by a corresponding AP-conjugated secondary antibody (dilution, 1:1,000). Proteins were visualized using nitro-blue tetrazolium and 5-bromo-4-chloro-3-indolyl phosphate.

Statistical analysis. All data represent $\geq 3$ independent experiments, and are expressed as the mean \pm standard deviation. 
A

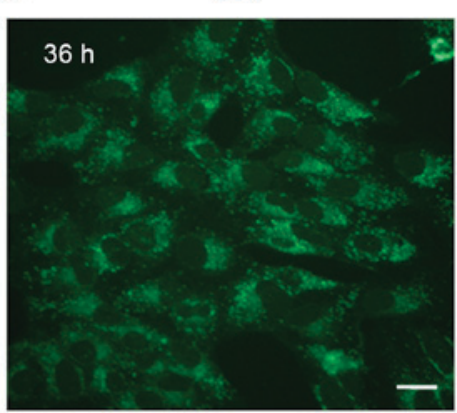

C

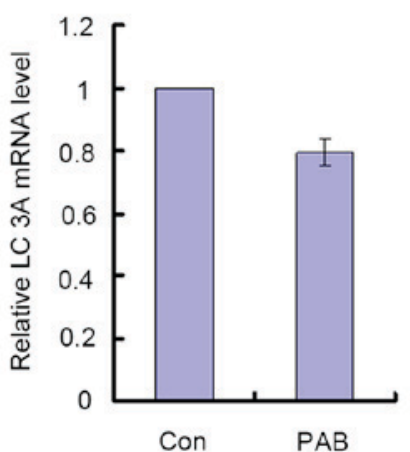

$\mathrm{PAB}$
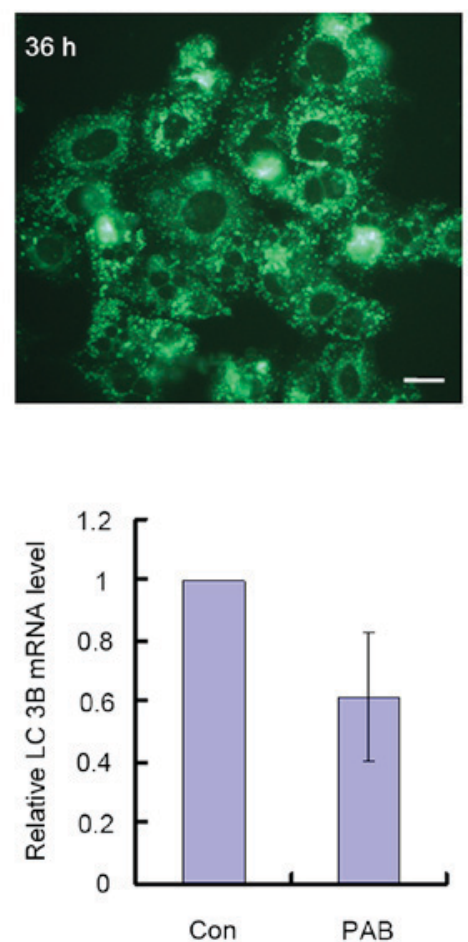

B
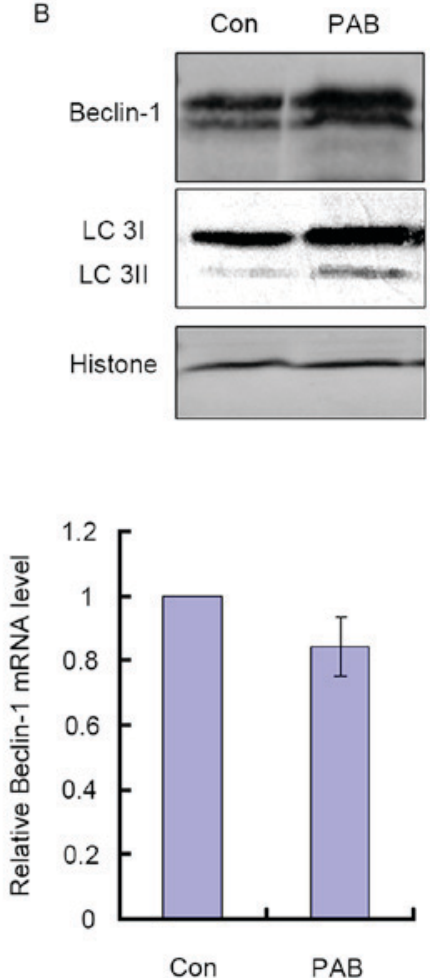

Figure 2. PAB induced autophagy in MRC5 cells. (A) Treatment with PAB increased the number of monodansylcadaverine-stained dots detected in fluorescence microscopy. Scale bar, $90 \mu \mathrm{m}$. (B) Expression of LC 3 and Beclin-1. A western blot was performed at $36 \mathrm{~h}$ after PAB treatment. Histone $\mathrm{H} 3$ is included as a loading control. (C) At $36 \mathrm{~h}$ after PAB treatment, intracellular LC 3A, LC 3B and Beclin-1 mRNA levels were detected. The results, as mean \pm standard deviation, were standardized to the expression of GAPDH mRNA and normalized to the control group. The results are representative of three independent experiments. PAB, pseudolaric acid B; LC 3, light chain 3; Con, control.

A

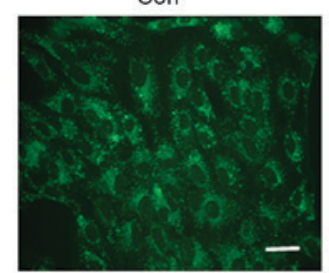

$B$

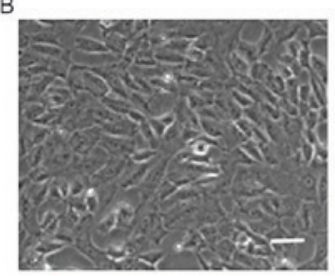

C

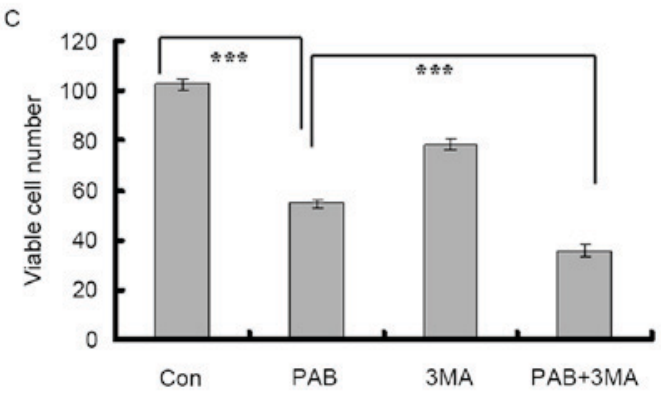

3MA
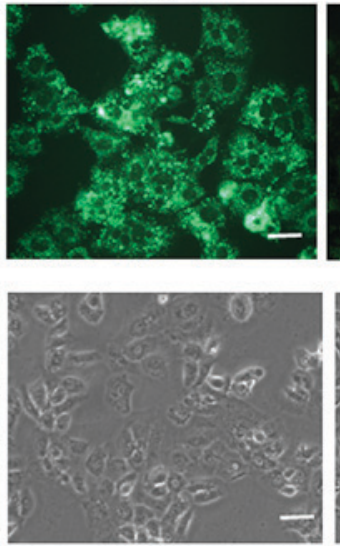

D
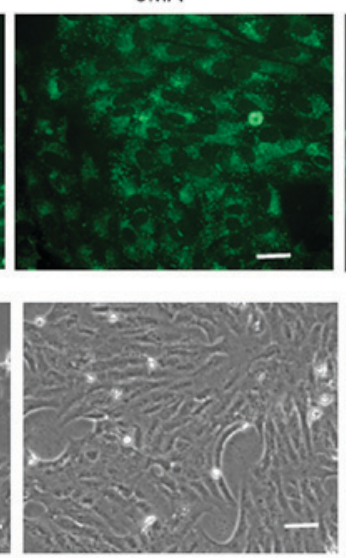

D $\quad M$

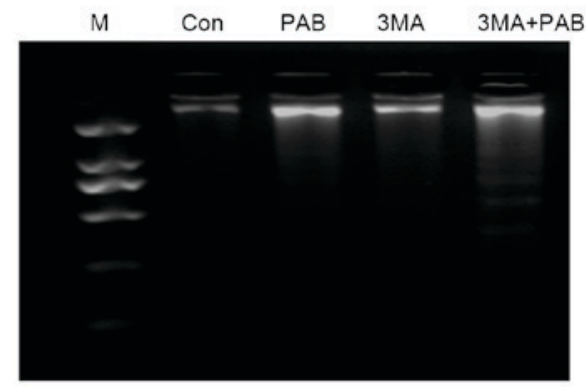

Figure 3. Inhibiting autophagy promoted apoptosis in MRC5 cells subsequent to PAB treatment. (A) At $36 \mathrm{~h}$ after PAB and/or $3 \mathrm{MA}$ treatment, the number of monodansylcadaverine-stained dots was observed with fluorescence microscopy. Scale bar, $45 \mu \mathrm{m}$. (B) At $36 \mathrm{~h}$ after PAB and/or $3 \mathrm{MA}$ treatment, the morphological changes of MRC5 cells were observed with phase contrast microscopy. Arrows indicate the cells undergoing cell death. Scale bar, $30 \mu \mathrm{m}$. (C) At $36 \mathrm{~h}$ after PAB and/or 3MA treatment the cell number was counted with trypan blue staining and imaged via light microscopy. The data are the means \pm standard deviation of 3 independent experiments. ${ }^{* * *} \mathrm{P}<0.001$. (D) Induction of chromosomal DNA fragmentation in cells treated with PAB and $3 \mathrm{MA}$. PAB, pseudolaric acid B; 3MA, 3-methyladenine; Con, control; M, marker. 
Statistical comparisons were made using Student's t-test in Microsoft Excel for the data in Fig. 2, and using a one-way analysis of variance with Dunnett's post-hoc test for Figs. 3 and 5 with SPSS 10.0 (SPSS, Inc., Chicago, IL, USA). $\mathrm{P}<0.05$ was considered to indicate a statistically significant difference.

\section{Results}

PAB does not induce apoptosis in MRC5 cells. In order to identify whether apoptosis was induced in MRC5 cells by treatment with PAB, the cellular and nuclear morphology was observed. At $36 \mathrm{~h}$, no characteristics of apoptosis, including the appearance of apoptotic bodies or cell condensation, were observed in PAB-treated cells (Fig. 1A). Following $36 \mathrm{~h}$ of PAB treatment, cell nuclei did not appear brighter, indicating that there was no induction of apoptosis, although multinuclear cells were observed (arrow, Fig. 1B). In the DNA ladder test, no DNA ladder was visible following $36 \mathrm{~h}$ of PAB treatment (Fig. 1C). Therefore, it was concluded that PAB treatment did not induce the apoptosis of MRC5 cells.

$P A B$ treatment induces autophagy in MRC5 cells. It was identified in our previous study that autophagy was induced by PAB treatment in the cells where apoptosis did not occur (4), so the rate of autophagy was assessed. It was observed that treatment with $4 \mu \mathrm{M}$ PAB increased the number of MDC positive points, indicative of autophagy (Fig. 2A). It was also identified that at $36 \mathrm{~h}$, LC3I and Beclin-1 protein expression were increased, and LC3I was converted into LC3II, which were also indications of autophagy (Fig. 2B). The mRNA levels of LC3A, LC3B and Beclin-1 were also quantified to ascertain whether they corresponded with the increase in protein expression; it was demonstrated that treatment with PAB did not significantly increase the mRNA levels for these genes relative to the control treatment group. The relative mRNA level of the PAB treatment group was $0.80 \pm 0.05$ for LC3A, $0.62 \pm 0.21$ for LC3B and $0.84 \pm 0.09$ for Beclin-1 compared with the control group (Fig. 2C). Therefore, PAB induced autophagy through upregulating autophagy-associated protein expression, whereas it did not affect the transcription of autophagy-associated genes.

Inhibiting autophagy promotes apoptosis in MRC5 cells treated with $P A B$. It was identified in our previous study that inhibiting autophagy subsequent to PAB treatment promoted apoptosis (4); it was assessed in the present study whether this also occurred in MRC5 cells. It was identified that PAB treatment increased the intensity of MDC staining; when combined with 3MA, an autophagy inhibitor, the intensity of MDC staining was decreased compared with PAB treatment alone (Fig. 3A). It was therefore demonstrated that 3MA inhibited the induction of autophagy by PAB treatment.

It was determined by morphological analysis that there was no induction of apoptosis subsequent to PAB treatment alone, whereas following treatment with a combination of 3MA and PAB, cells detaching from the base could be observed (black arrow, Fig. 3B). At $36 \mathrm{~h}$, the total number of viable cells was $54.75 \pm 1.71$ in the PAB-treated group and $102.50 \pm 2.08$ for the control group (Fig. $3 \mathrm{C}$; $\mathrm{P}<0.001$ ). In the $\mathrm{PAB}$ and $3 \mathrm{MA}$
A

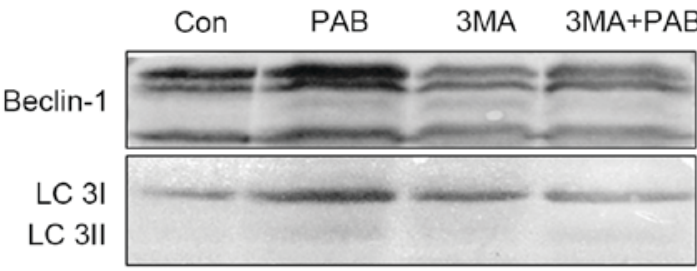

B
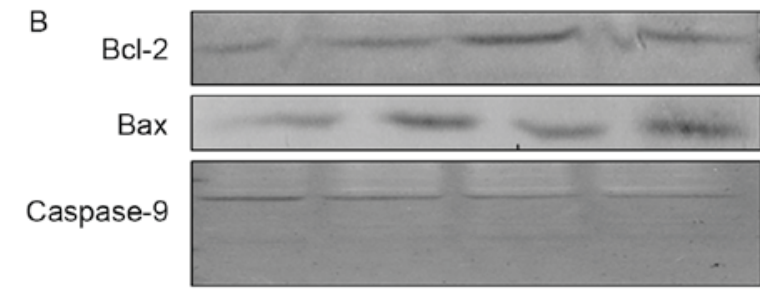

C Fas

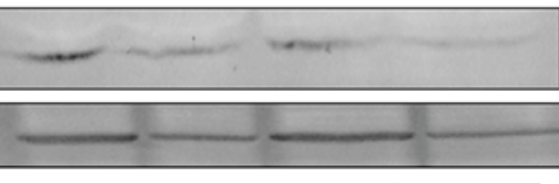

Caspase-

D
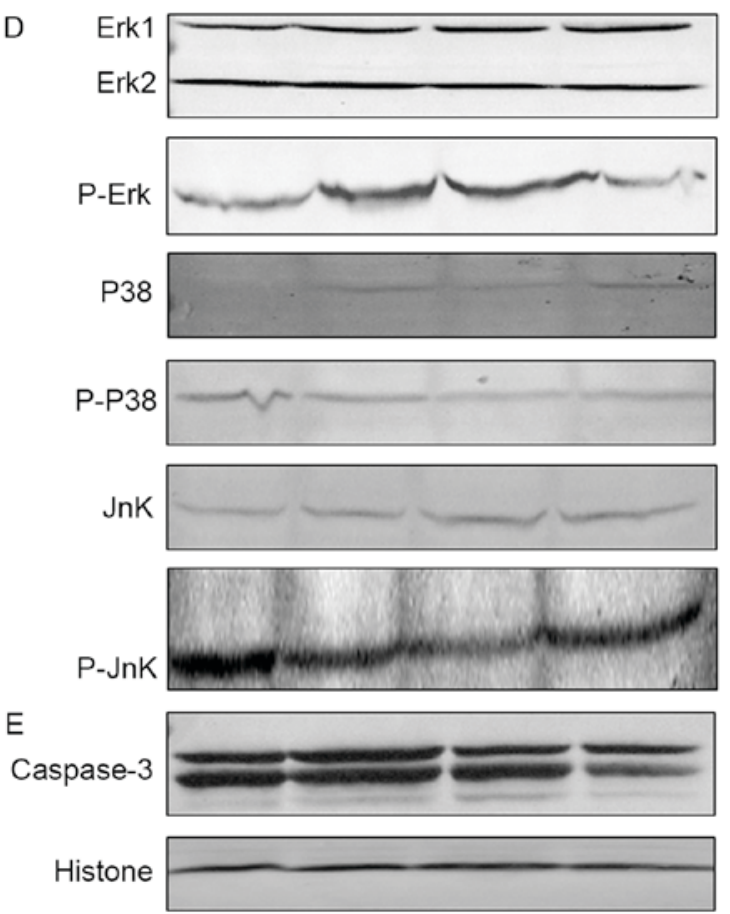

Figure 4. Expression of apoptosis-associated proteins following treatment with PAB and/or 3MA. (A) Beclin-1 and LC 3 expression. (B) Bcl-2, Bax and pro-caspase-9 expression. (C) Fas and pro-caspase-8 expression. (D) p38, p-p38, Jnk, p-Jnk, Erk and p-Erk expression. (E) Pro-caspase-3 expression, and histone $\mathrm{H} 3$ as a loading control. PAB, pseudolaric acid B; 3MA, 3-methyladenine; LC 3, light chain 3; Bax, Bcl-2 associated X; p, phosphorylated; Jnk, Jun N-terminal kinase; Erk, extracellular signal-related kinase; Con, control.

combination group, the number of viable cells was 36.00 \pm 2.58 , which was significantly lower than in the PAB treatment group (Fig. 3C; $\mathrm{P}<0.001$ ). Therefore, it was concluded that inhibiting autophagy may have promoted cell death. It was finally determined whether inhibiting autophagy promoted apoptosis with a DNA ladder test; it was confirmed that following PAB treatment, there was no DNA ladder, indicating no apoptosis, whereas when combined with $3 \mathrm{MA}, \mathrm{PAB}$ treatment induced the appearance of a DNA ladder (Fig. 3D). Therefore, inhibiting autophagy promoted apoptosis in the MRC5 cells treated with PAB. 
A
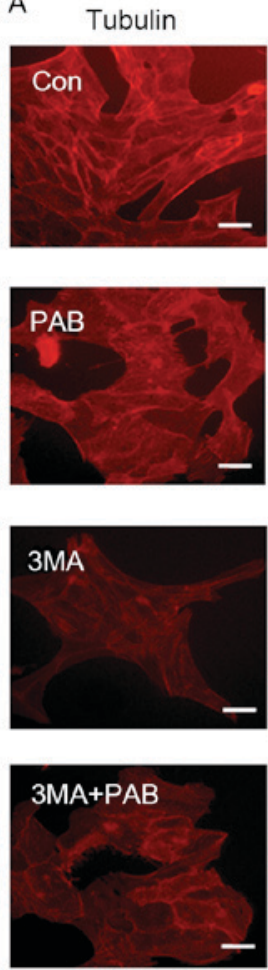

Nuclei
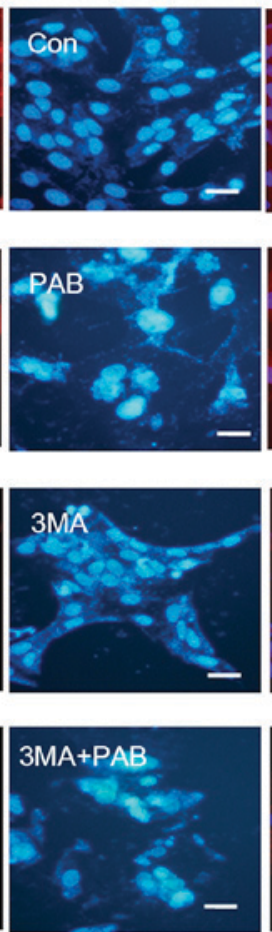
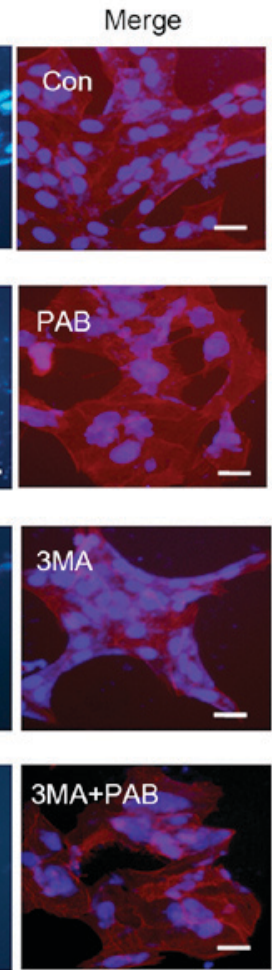
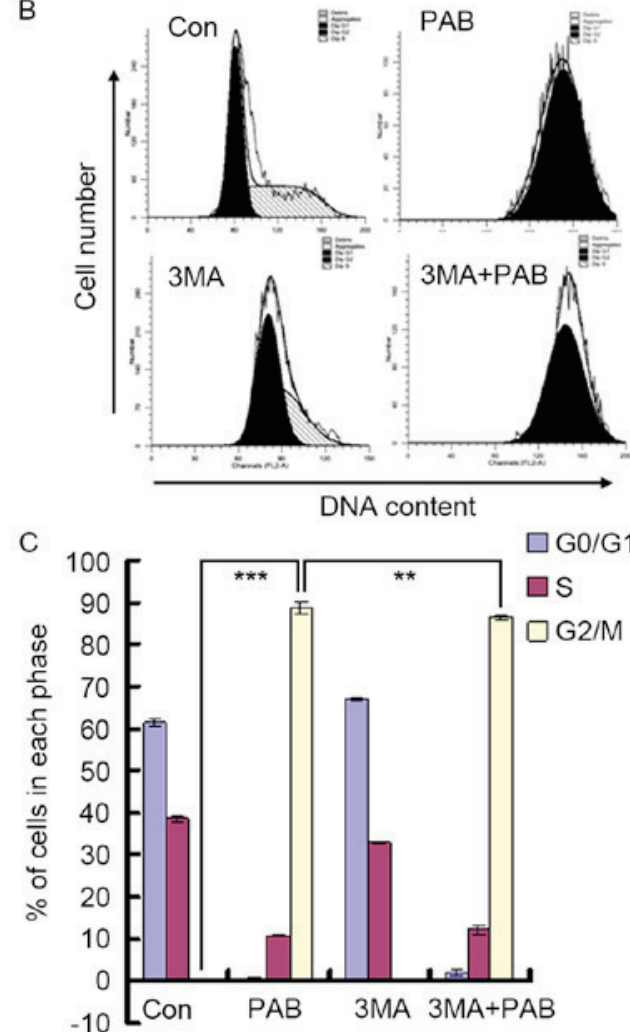

Figure 5. Inhibiting autophagy had no effect on the aggregation of microtubules and reduced the extent of cell cycle arrest induced by PAB. (A) Tubulin distribution and nuclear alterations analysis of PAB-treated MRC5 cells, as detected with fluorescence microscopy following phalloidin-tetramethylrhodamine B isothiocyanate and Hoechst 33258 staining. Scale bar, $60 \mu \mathrm{m}$. (B) Cell cycle profiles as determined by flow cytometry at $36 \mathrm{~h}$. (C) Histograms of the percentage of cells in each phase of the cell cycle. The data are means \pm standard deviation. ${ }^{* *} \mathrm{P}<0.01 ;{ }^{* * *} \mathrm{P}<0.001$. The results are representative of three independent experiments. PAB, pseudolaric acid B; Con, control; 3MA, 3-methyladenine.

Apoptosis is induced in MRC5 cells treated with PAB and $3 M A$ via the upregulation of $p$-Jnk and the downregulation of $p$-Erk. As it had been demonstrated that 3MA inhibited autophagy and promoted apoptosis in MRC5 cells co-treated with PAB, the mechanism by which 3MA prevented autophagy and induced apoptosis was investigated. PAB treatment upregulated the expression of the autophagy-associated proteins Beclin-1 and LC 3A/B. Following treatment with 3MA, the upregulation of Beclin-1 and LC 3A/B expression by PAB treatment was inhibited (Fig. 4A).

The role of the mitochondrial pathway in PAB and/or 3MA treated cells was assessed; compared with $\mathrm{PAB}$ treatment, $\mathrm{PAB}$ and 3MA co-treatment did not affect the expression of Bcl-2, Bax or pro-caspase-9 (Fig. 4B); it was therefore concluded that 3MA promoted the apoptosis of PAB-treated cells dependent of the mitochondrial pathway.

The expression of proteins from the death receptor-dependent pathway in PAB and/or 3MA treated cells was also considered, and it was confirmed that compared with the PAB treatment group, the PAB and 3MA combination group exhibited similar expression of Fas and pro-caspase-8 (Fig. 4C); it was therefore concluded that 3MA promoted the apoptosis of PAB-treated cells dependent of the death receptor pathway.

Finally, the effects on the MAPK pathway of PAB and/or 3MA treatment were investigated; it was observed that compared with $\mathrm{PAB}$ treatment alone, PAB combined with 3MA did not alter the expression of p38, p-p38, Jnk or Erk, whereas the expression of p-Jnk and p-Erk was altered
(Fig. 4D); therefore, it was concluded that 3MA treatment upregulated the phosphorylation of Jnk and downregulated the phosphorylation of Erk to promote apoptosis in PAB-treated cells. It was noted that the expression of pro-caspase-3 was reduced in the combination treatment group compared with PAB alone (Fig. 4E); therefore, 3MA promoted caspase-3 activation independent of caspase- 8 and -9 .

Inhibiting autophagy does not affect the aggregation of microtubule fibers induced by $P A B$. In a previous study, it was identified that the function of PAB was mediated through affecting the aggregation of microtubule fibers (24). In the present study, it was observed that PAB treatment promoted the aggregation of microtubule fibers; combination treatment with 3MA did not prevent this effect (Fig. 5A). PAB treatment induced $\mathrm{G}_{2} / \mathrm{M}$ cell cycle arrest in MRC5 cells $\left(\mathrm{G}_{2} / \mathrm{M}\right.$ proportion, $88.78 \pm 1.34 \%$ ), whereas 3MA decreased the proportion of $\mathrm{G}_{2} / \mathrm{M}$ phase cells following treatment with PAB $(86.44 \pm 0.66 \%$; $\mathrm{P}<0.01$; Fig. 5B and C). Therefore, the inhibition of autophagy had no effect on the aggregation of microtubule fibers, whereas the extent of cell cycle arrest induced by PAB was reduced.

\section{Discussion}

Autophagy is an intracellular pathway for the bulk degradation of damaged proteins and organelles in the lysosome/vacuole that recycles material for biosynthesis and cellular energy production in stress conditions (25). Its role in cancer is 
complex and controversial; it may act as a tumor-promoting or a tumor-suppressive mechanism depending on the cellular context and genetic background (26). Autophagy and apoptosis may interact with each other, and a number of the molecular constituents in this interplay have been identified $(27,28)$.

In previous studies, it was demonstrated that $\mathrm{PAB}$ induced the apoptosis of A375-S2 human melanoma (2), MCF-7 human breast cancer (5) and HeLa human cervical carcinoma (1) cells. However, in L929 murine fibrosarcoma (4) and SW579 human thyroid squamous cell carcinoma (22) cells, PAB induced autophagy without apoptosis. The cells in which autophagy was induced without apoptosis were considered as potential models for the study of the association of apoptosis and autophagy. As L929 cells are murine (4), they were considered imperfect for the study of the mechanisms in human cells; as SW579 cells are cultured without $\mathrm{CO}_{2}(22)$, they were considered relatively inconvenient. Therefore, MRC5 cells were selected for use as a model in the present study to study the association between autophagy and apoptosis following PAB treatment, as the MRC5 cell line is human and it has a proliferative ability, which mimics human cancer cell behavior.

In the present study, it was confirmed through cell and nuclear morphology analysis, and a DNA ladder test, that PAB did not induce apoptosis in MRC5 cells. It was also confirmed, through MDC staining, and the determination of autophagy-associated protein and mRNA expression, that PAB induced autophagy. It was therefore concluded that in MRC5 cells, PAB only induced autophagy, and not apoptosis. To the best of our knowledge, the mechanism by which PAB did not induce apoptosis in SW579, L929 and MRC5 cells was never previously identified. We hypothesized that the cell lines lacked the expression of a key factor in the initiation of apoptosis; therefore, when PAB treatment activated an upstream signal, autophagy occurred without apoptosis.

Autophagy typically delays or prevents apoptosis, although it may also promote apoptosis (29). In addition to apoptosis, autophagy may affect tumor immunity; it has been identified that cancer cell autophagy serves a critical function in subverting anti-tumor immunity (30). To further establish a relationship between apoptosis and autophagy, 3MA was used to inhibit the autophagy induced by PAB in the present study. It was revealed that inhibiting autophagy promoted apoptotic cell death. Therefore, it was demonstrated that in MRC5 cells treated with PAB, autophagy inhibited apoptosis. It has thus been identified that L929, SW579 and MRC5 cells undergo autophagy without apoptosis as a response to PAB treatment; however, the common characteristics of these cells that may underlie this effect have yet to be identified and require further study. As autophagy inhibits anti-tumor immunity (30) in addition to apoptosis, in the development of anti-tumor drugs, including PAB, inhibiting autophagy may be important.

The mechanisms for the inhibition of autophagy and the promotion of apoptosis were investigated in the present study by examining the expression of proteins from the major pathways of apoptosis. Subsequent to the inhibition of autophagy with 3MA in PAB-treated cells, the expression of proteins from the mitochondrial and death receptor pathways was not altered compared with treatment with PAB alone, whereas the expression of caspase- 3 was activated. It was therefore concluded that caspase- 3 activation was not dependent on the mitochondrial or death receptor pathways of apoptosis. It was identified that the expression of p38 was unaffected, whereas Jnk was activated and Erk was inactivated, following 3MA treatment in PAB treated cells compared with PAB alone, therefore 3MA may have inhibited autophagy and promoted apoptosis through the upregulation of p-Jnk expression and the downregulation of p-Erk expression, and caspase-3 activation might be the downstream of Jnk and Erk protein.

The effect of PAB on microtubules and the induction of cell cycle arrest was previously identified in other cell lines $(24,31)$. In the present study, the aggregation of microtubules and cell cycle arrest were also identified as a response to PAB treatment, but following the inhibition of autophagy by $3 \mathrm{MA}$, the aggregation of microtubules was unaffected, and the proportion of cells in $\mathrm{G}_{2} / \mathrm{M}$ was only decreased from 88.78 to $86.44 \%$. Therefore, autophagy may be downstream of the aggregation of microtubules and cell cycle arrest. In conclusion, inhibiting autophagy did not affect the microtubule aggregation role of PAB and promoted cell apoptosis. Inhibiting autophagy should be considered as a means to enhance the anticancer effect of PAB treatment.

\section{Acknowledgements}

The present study was supported by funding from the National Natural Science Foundation of China (grant no., 81301416), the Postdoctoral Science Foundation of China (grant nos, 2014M561302 and 2015T80299), the Norman Bethune Program of Jilin University (grant no, 2015202), the Jilin Provincial Science and Technology Department (grant nos, 20140204004YY and 20160414025GH), and the Department of Human Resources and Social Security of Jilin Province (grant no., 2016014).

\section{References}

1. Gong $\mathrm{X}$, Wang $\mathrm{M}$, Tashiro $\mathrm{S}$, Onodera $\mathrm{S}$ and Ikejima T: Involvement of JNK-initiated p53 accumulation and phosphorylation of p53 in pseudolaric acid B induced cell death. Exp Mol Med 38: 428-434, 2006.

2. Gong XF, Wang MW, Tashiro S, Onodera S and Ikejima T: Pseudolaric acid B induces apoptosis through p53 and Bax/Bcl-2 pathways in human melanoma A375-S2 cells. Arch Pharm Res 28: 68-72, 2005.

3. Pan DJ, Li ZL, Hu CQ, Chen K, Chang JJ and Lee KH: The cytotoxic principles of Pseudolarix kaempferi: Pseudolaric acid-A and -B and related derivatives. Planta Med 56: 383-385, 1990.

4. Yu J, Li X, Tashiro S, Onodera S and Ikejima T: Bcl-2 family proteins were involved in pseudolaric acid B-induced autophagy in murine fibrosarcoma L929 cells. J Pharmacol Sci 107: 295-302, 2008.

5. Yu JH, Cui Q, Jiang YY, Yang W, Tashiro S, Onodera S and Ikejima T: Pseudolaric acid B induces apoptosis, senescence, and mitotic arrest in human breast cancer MCF-7. Acta Pharmacol Sin 28: 1975-1983, 2007.

6. Yu JH, Wang HJ, Li XR, Tashiro S, Onodera S and Ikejima T: Protein tyrosine kinase, JNK, and ERK involvement in pseudolaric acid B-induced apoptosis of human breast cancer MCF-7 cells. Acta Pharmacol Sin 29: 1069-1076, 2008.

7. Li FF, Yi S, Wen L, He J, Yang LJ, Zhao J, Zhang BP, Cui GH and Chen Y: Oridonin induces NPM mutant protein translocation and apoptosis in NPM1c+ acute myeloid leukemia cells in vitro. Acta Pharmacol Sin 35: 806-813, 2014.

8. Qi M, Yao G, Fan S, Cheng W, Tashiro S, Onodera S and Ikejima T: Pseudolaric acid B induces mitotic catastrophe followed by apoptotic cell death in murine fibrosarcoma L929 cells. Eur J Pharmacol 683: 16-26, 2012.

9. Adams JM: Ways of dying: Multiple pathways to apoptosis. Genes Dev 17: 2481-2495, 2003. 
10. Nagata S and Golstein P: The Fas death factor. Science 267: 1449-1456, 1995.

11. Klekotka PA, Santoro SA, Wang H and Zutter MM: Specific residues within the alpha 2 integrin subunit cytoplasmic domain regulate migration and cell cycle progression via distinct MAPK pathways. J Biol Chem 276: 32353-32361, 2001.

12. Xia Z, Dickens M, Raingeaud J, Davis RJ and Greenberg ME: Opposing effects of ERK and JNK-p38 MAP kinases on apoptosis. Science 270: 1326-1331, 1995.

13. Yoon $\mathrm{S}$ and Seger R: The extracellular signal-regulated kinase: Multiple substrates regulate diverse cellular functions. Growth Factors 24: 21-44, 2006.

14. Lee YJ, Won AJ, Lee J, Jung JH, Yoon S, Lee BM and Kim HS Molecular mechanism of SAHA on regulation of autophagic cell death in tamoxifen-resistant MCF-7 breast cancer cells. Int J Med Sci 9: 881-893, 2012.

15. Lee YZ, Yang CW, Chang HY, Hsu HY, Chen IS, Chang HS, Lee CH, Lee JC, Kumar CR, Qiu YQ, et al: Discovery of selective inhibitors of Glutaminase-2, which inhibit mTORC1, activate autophagy and inhibit proliferation in cancer cells. Oncotarget 5: 6087-6101, 2014

16. He H, Feng YS, Zang LH, Liu WW, Ding LQ, Chen LX, Kang N, Hayashi T, Tashiro S, Onodera S, et al: Nitric oxide induces apoptosis and autophagy; autophagy down-regulates NO synthesis in physalin A-treated A375-S2 human melanoma cells. Food Chem Toxicol 71: 128-135, 2014.

17. Livak KJ and Schmittgen TD: Analysis of relative gene expression data using real-time quantitative PCR and the 2(-Delta Delta C(T)) method. Methods 25: 402-408, 2001

18. Wang ZY, Zhong T, Wang Y, Song FM, Yu XF, Xing LP, Zhang WY, Yu JH, Hua SC and Yu XF: Human enterovirus 68 interferes with the host cell cycle to facilitate viral production. Front Cell Infect Microbiol 7: 29, 2017.

19. Zhong T, Zhang LY, Wang ZY, Wang Y, Song FM, Zhang YH and Yu JH: Rheum emodin inhibits enterovirus 71 viral replication and affects the host cell cycle environment. Acta Pharmacol Sin 38: 392-401, 2017

20. Liu YQ, Han XF, Bo JX and Ma HP: Wedelolactone enhances osteoblastogenesis but inhibits osteoclastogenesis through Sema3A/NRP1/PlexinA1 pathway. Front Pharmacol 7: 375, 2016.

21. Yu J, Chen C, Xu T, Yan M, Xue B, Wang Y, Liu C, Zhong T, Wang Z, Meng X, et al: Pseudolaric acid B activates autophagy in MCF-7 human breast cancer cells to prevent cell death. Oncol Lett 11: 1731-1737, 2016.
22. Yu J, Ren P, Zhong T, Wang Y, Yan M, Xue B, Li R, Dai C, Liu C, Chen G and Yu XF: Pseudolaric acid B inhibits proliferation in SW579 human thyroid squamous cell carcinoma. Mol Med Rep 12: 7195-7202, 2015.

23. Yu J, Wang Z, Ren P, Zhong T, Wang Y, Song F, Hou J, Yu X and Hua S: Pseudolaric acid B inhibits the secretion of hepatitis B virus. Oncol Rep 37: 519-525, 2017.

24. Wong VK, Chiu P, Chung SS, Chow LM, Zhao YZ, Yang BB and Ko BC: Pseudolaric acid B, a novel microtubule-destabilizing agent that circumvents multidrug resistance phenotype and exhibits antitumor activity in vivo. Clin Cancer Res 11: 6002-6011, 2005.

25. Feng Y, He D, Yao Z and Klionsky DJ: The machinery of macroautophagy. Cell Res 24: 24-41, 2014.

26. Galluzzi L, Pietrocola F, Bravo-San Pedro JM, Amaravadi RK, Baehrecke EH, Cecconi F, Codogno P, Debnath J, Gewirtz DA Karantza V, et al: Autophagy in malignant transformation and cancer progression. EMBO J 34: 856-880, 2015.

27. Crighton D, Wilkinson S, O'Prey J, Syed N, Smith P, Harrison PR, Gasco M, Garrone O, Crook T and Ryan KM: DRAM, a p53-induced modulator of autophagy, is critical for apoptosis. Cell 126: 121-134, 2006

28. Behrends C, Sowa ME, Gygi SP and Harper JW: Network organization of the human autophagy system. Nature 466: 68-76, 2010.

29. Mariño G, Niso-Santano M, Baehrecke EH and Kroemer G: Self-consumption: The interplay of autophagy and apoptosis. Nat Rev Mol Cell Biol 15: 81-94, 2014.

30. Salah FS, Ebbinghaus M, Muley VY, Zhou Z, Al-Saadi KR, Pacyna-Gengelbach M, O'Sullivan GA, Betz H, König R, Wang ZQ, et al: Tumor suppression in mice lacking GABARAP, an Atg8/LC3 family member implicated in autophagy, is associated with alterations in cytokine secretion and cell death. Cell Death Dis 7: e2205, 2016.

31. Tong YG, Zhang XW, Geng MY, Yue JM, Xin XL, Tian F, Shen X, Tong LJ, Li MH, Zhang C, et al: Pseudolarix acid B, a new tubulin-binding agent, inhibits angiogenesis by interacting with a novel binding site on tubulin. Mol Pharmacol 69: 1226-1233, 2006.

This work is licensed under a Creative Commons Attribution-NonCommercial-NoDerivatives 4.0 International (CC BY-NC-ND 4.0) License. 